\title{
QUESTIONNAIRE BASED STUDY ON MENSTRUAL PATTERNS AMONG FEMALE MEDICAL UNIVERSITY STUDENTS OF RURAL NORTH INDIA
}

\author{
Bindoo Yadav1, Poonam Taneja ${ }^{2}$ \\ ${ }_{1}^{1}$ Associate Professor, Department of Obstetrics and Gynaecology, SGT Medical College Hospital and Research Institute, SGT University, \\ Budhera, Gurugram, Haryana, India. \\ ${ }^{2}$ Associate Professor, Department of Obstetrics and Gynaecology, SGT Medical College Hospital and Research Institute, SGT University, \\ Budhera, Gurugram, Haryana, India.
}

\begin{abstract}
\section{BACKGROUND}

Menstruation is unique phenomenon in girls. However, even in today's time in India, it is associated with many taboos and myths that affect many socio-cultural and economic aspects of life and is a hindrance in the overall development of a girl to women and becoming empowered. Besides the taboos, there are menstrual problems which a girl has to suffer. A woman's reproductive health is determined by her menstrual health. The prevalence of menstrual disorders is highest in the 20 to 24 -year-old age group and decreases progressively thereafter. They affect not only the woman, but also family, social, and national economics as well. Even girls from good socioeconomic background and education are unable to dispel the taboos and are unable to discuss their menstrual issues and problems due to lack of menstrual education. Information on a woman's menstrual pattern will aid in clinical evaluation of gynaecological problems and will make womanhood easier for adolescent women and adults ${ }^{1}$. However, studies on menstrual pattern, menstrual disorders, associated factors and taboos affecting the girls of medical students of university of rural North India are very few. We wanted to determine the menstrual pattern, menstrual disorders, information regarding menstruation and taboos associated with menstruation among female medical students of university of rural North India.
\end{abstract}

\begin{abstract}
METHODS
A self-descriptive cross-sectional study was carried out among female medical students between the ages 17-22 years. A total of 235 questionnaires was administered to postmenarcheal Indian adolescent girls attending medical college in SGT University, Gurugram, and Haryana India. Participants were asked to respond to a semi-structured questionnaire on menstrual health awareness. The questionnaire included questions on age at menarche, menstrual cycle length and regularity, duration, and amount of flow, type and severity of pain related to menstruation, need for analgesia, and symptoms suggestive of premenstrual syndrome (PMS), and impact of menstrual pain on academic and social activities and taboos associated with menstruation. The main outcome measure was information regarding menarche, description of menstrual patterns, disorders and impact of the disorder on academic and social activities and taboos regarding menstruation.
\end{abstract}

\section{RESULTS}

Out of the 235 questionnaires distributed, 200 were retrieved and the information contained in each questionnaire was analysed. The mean age of menarche was $12.59 \pm 1.25$ years with a range of 10 to 16 years. The mean age of girls was $19.45 \pm 2.5$ years. Mean duration of menstrual flow was $4.77 \pm 1.06$ days. It was observed that $146(72 \%)$ respondents had regular length of menstrual cycle whereas 54 (28\%) respondents had irregular menstrual cycle, which showed its peak at the age group of 17-19yrs. (33.3\%) between age groups. Of the 146 students with regular menstrual cycle, 88 (60.27\%) had average flow while in 40 (27.39\%) had scanty, and $18(12.32 \%)$ had heavy menstrual cycle. Of the 54 students who had irregular cycle, prolonged cycles were reported by 42 (77.77\%) students, and frequent cycles were reported by 12 (22.22\%) students. Dysmenorrhoea was reported in 140 (70\%) respondents. Of these, 70 (50\%) had mild, 48 (34.28\%) had moderate and $22(15.72 \%)$ had severe pain. Premenstrual syndrome was mentioned by $64(32 \%)$ girls. 65 (53.27\%) of the dysmenorrheic girls reported that their working ability was affected. 130 (65\%) of the girls were aware of menstruation prior to menarche. Mothers, sisters and friends were the main sources of information 148 (74\%). 29\% missed social activities, and 12.5\% missed college, due to menstrual problems. 110 (55\%) needed drugs to treat menstrual disorders. 82.5\% girls had misconceptions and taboos related to menstruation.

\section{CONCLUSIONS}

Mean age at menarche is in sync with global trend with gradual fall in the age of menarche. There is high prevalence of dysmenorrhoea, PMS, and abnormal menstrual length which requires attention and treatment. These disorders are affecting the working ability, lead to college absenteeism and social withdrawal. Also, even though they are medical students, they still have taboos related to menstruation, which they believe in, and consider many menstrual disorders as normal and are hesitant to come out and discuss with the physician. They are mostly either bearing the problem, or self-medicating. There are many menstrual taboos which are affecting their socio-cultural and economic aspects. Increasing the awareness through educational programs at early age will definitely help the girl in developing confidence and increases self-esteem.

HOW TO CITE THIS ARTICLE: Yadav B, Taneja P. Questionnaire based study on menstrual patterns among female medical university students of rural North India. J. Evolution Med. Dent. Sci. 2019;8(15):1232-1236, DOI: 10.14260/jemds/2019/273 
'Financial or Other Competing Interest': None

Submission 18-02-2019, Peer Review 29-03-2019,

Acceptance 05-04-2019, Published 15-04-2019.

Corresponding Author:

Poonam Taneja,

Department of Obstetrics and Gynaecology,

1180, Sector-4, Gurugram-122001,

Haryana, India.

E-mail: taneja-poonam@rediffmail.com

DOI: $10.14260 /$ jemds $/ 2019 / 273$

\section{(c) $(1) \ominus$}

\section{BACKGROUND}

Women's first menstruation is called menarche. It is an important maturity indicator used to assess the development status of a pubertal female. Menstruation is the natural part of the reproductive cycle. ${ }^{2}$ One of the most common gynaecologic complaints in young women who present to the clinicians is Dysmenorrhoea. ${ }^{3}$ Disorders in cycles or its irregularities are a major gynaecological problem among female adults especially adolescent and a major source of anxiety to them and their family. Premenstrual syndrome (PMS) is another problem that some women experience during the late luteal phase of each menstrual cycle (7-14 days prior to menstruation). Although various aetiologies of premenstrual syndrome such as elevated prolactin levels, hypoglycaemia or vitamin deficiencies have been proposed, none of these theories has been definitely proven.4,5 Despite being a regular phenomenon the menstruation has been surrounded by secrecy and myths in many societies which affect many aspects of social and cultural life. ${ }^{6}$

Information on a women's menstrual pattern aids in clinical evaluation of gynaecological problems and will make womanhood easier for adolescent women and adults.

\section{Procedure}

This Self-descriptive cross-sectional study was conducted to determine age at menarche, menstrual cycle length and regularity, duration and amount of flow, type and severity of pain related to menstruation, need for analgesia, and symptoms suggestive of premenstrual syndrome (PMS), impact of menstrual pain on academic and social activities, taboos related to menstruation and need of analgesia and treatment taken. Also, to infer the extent of awareness and source of information regarding menstruation possessed by Indian girls before attaining puberty.

The questionnaire included questions on concerning their age at menarche, menstrual cycle length and regularity, duration and amount of flow, type and severity of pain related to menstruation, need for analgesics, symptoms suggestive of premenstrual syndrome (PMS) and taboos related to menstruation. Respondents were also asked about the impact of menstruation and its disorders on the social life and academic activity. Other variables of interest included; any additional menstrual related symptoms or gynaecologic symptoms not mentioned in the questionnaire, source of information regarding menstrual health knowledge and academic performance were the main sources of information.

\section{Aims \& Objectives}

To determine the menstrual pattern, menstrual disorders, information regarding menstruation and taboos associated with menstruation among female medical students of university of rural North India.

\section{METHODS}

Self-descriptive cross-sectional study was carried out among female Medical students (MBBS I-V) between the ages 17-24 years. A Total of 235 questionnaires were administered to postmenarcheal Indian female students attending medical college in SGT University, Gurugram, Haryana between August 2017 - July 2018. India. The sample size of 235 patients were taken for convenience.

\section{Inclusion Criteria}

MBBS girl students aged between 17 to 24 years, menstruating, and unmarried; those students who cooperated to provide correct and complete information and fitted into the study criteria were included for the study.

Respondents were selected from each class using stratified random sampling method. Students were briefed on the objective of the study and duly completed questionnaires were collected and analysed.

\section{Statistical Analysis}

The data were analysed using SPSS for Windows version 16.0. Descriptive statistics was used to determine mean age of the subjects, age at menarche, frequency of menstrual disorders, prevalence of dysmenorrhea, PMS and activities affected by this condition.

\section{RESULTS}

Out of the 235 students, 200 responded to the questionnaire. The mean age of the female medical students was $19.45 \pm 2.5$ years. The mean age of menarche was $12.59 \pm 1.25$ years exhibiting wide variations, i.e., 10 to 16 years among the participants. Most respondents 184 (92\%) menstruated by the age of 15.

Menstrual characteristics as indicated by the selected subjects are presented in Table 1.

\begin{tabular}{|c|c|c|c|}
\hline \multicolumn{2}{|c|}{ Characteristics } & Frequency (N) & (\%) \\
\hline \multirow{2}{*}{$\begin{array}{c}\text { Menstrual Cycle } \\
\text { Length (days) }\end{array}$} & $<20$ & 21 & $10.5 \%$ \\
\cline { 2 - 4 } & $>35$ & 131 & $65.5 \%$ \\
\hline \multirow{2}{*}{$\begin{array}{c}\text { Duration of } \\
\text { Menstrual }\end{array}$} & $<2$ & 48 & $24 \%$ \\
\cline { 2 - 4 } Flow/No. of Days & $2-6$ & 181 & $4.5 \%$ \\
\cline { 2 - 4 } Regularity of & \multicolumn{1}{|c|}{ Regular Cycle } & $10.5 \%$ \\
\cline { 2 - 4 } Menstrual Cycles & Irregular Cycle & 69 & $5 \%$ \\
\hline Table 1. Showing Various Menstrual Characteristics \\
\hline
\end{tabular}

Regular menses occurred in $65.5 \%(n=131 / 200)$ of girls; a cycle length ranging from 21 to 35 days (Mean, $27.58 \pm 1.79$ days) and the mean duration of menstruation was $4.77 \pm 1.06$ days with a range of $2-8$ days. The pattern of menstrual related morbidities, additional symptoms reported by participants and treatment patterns are shown in Table 1.

\begin{tabular}{|c|c|c|c|}
\hline \multirow{3}{*}{ Dysmenorrhea } & No Dysmenorrhoea & 60 & $30 \%$ \\
\cline { 2 - 4 } & Mild & 70 & $50 \%$ \\
\cline { 2 - 4 } & Moderate & 48 & $34.28 \%$ \\
\cline { 2 - 4 } & Severe & 22 & $15.72 \%$ \\
\hline \multirow{2}{*}{ PMS } & Absent & 136 & $68 \%$ \\
\cline { 2 - 4 } & Present & 64 & $32 \%$ \\
\hline \multirow{2}{*}{$\begin{array}{c}\text { Abnormal } \\
\text { Cycle Lengths }\end{array}$} & Absent & 146 & $73 \%$ \\
\cline { 2 - 4 } & Prolonged Cycle & 42 & $21 \%$ \\
\cline { 2 - 4 } & Frequent Cycle & 12 & $6 \%$ \\
\hline \multicolumn{3}{|c|}{ Table 2. Showing Various Menstrual Complaints } \\
\hline
\end{tabular}


166 respondents reported various menstrual disorders, giving a prevalence rate of $83 \%$. Dysmenorrhea was the most prevalent $140(70 \%)$ menstrual disorder in our sample, followed by PMS 64 (32\%), and abnormal cycle lengths 54 (27.5\%)

Of the $140(70 \%)$ girls who reported dysmenorrhoea 70 (50\%) had mild, 48 (34.28\%) moderate and 22 (15.72\%) had severe dysmenorrhea.

\begin{tabular}{|c|c|c|}
\hline No Need & 90 & $45 \%$ \\
\hline Self-Medication & 44 & $22 \%$ \\
\hline Treatment Given by Parents & 30 & $15 \%$ \\
\hline Treatment Given by A Doctor & 36 & $18 \%$ \\
\hline \multicolumn{2}{|c|}{ Table 3. Showing Need of Treatment } \\
\hline
\end{tabular}

Despite the fact that girls are studying in a medical college still only $36(18 \%)$ are consulting a doctor for help.

Overall, menstrual disorders prevented 29\% ( $n=58)$ of students from participating in social activities and 12.5\% $(n=25)$ from attending college.

Dysmenorrhea was responsible for the highest rate of college absenteeism (61\%) followed by PMS (38\%). The majority of absences (58\%) were for 1 day, with $32 \%$ for up to 2 days and 3 girls reported missing up to 4 days of college each cycle.

\begin{tabular}{|c|c|c|}
\hline No Information & 31 & $16.5 \%$ \\
\hline Mom/Sister & 77 & $38.5 \%$ \\
\hline Friends & 71 & $35.5 \%$ \\
\hline Doctor/Nurse & 5 & $2.5 \%$ \\
\hline Mass Media & 16 & $8 \%$ \\
\hline Table 4. Depicting Awareness Before Menarche
\end{tabular}

Table 4. Depicting Awareness Before Menarche

$169(83.5 \%)$ of participants were aware of menstruation before attaining menarche. Source for information varied from mothers and friends to TV, magazines, and newspaper; nevertheless, the major sources were mothers and friends 148 (74\%).

\begin{tabular}{|c|c|c|}
\hline No Misconception & 35 & $\mathbf{1 7 . 5 \%}$ \\
\hline Do not enter temple & 141 & $70.5 \%$ \\
\hline Do not sleep on bed & 34 & $17 \%$ \\
\hline Do not enter kitchen & 56 & $28 \%$ \\
\hline Do not wash head during mensus & 46 & $23 \%$ \\
\hline Do not touch holy books & 108 & $54 \%$ \\
\hline Women are unhygienic during mensus & 51 & $25.5 \%$ \\
\hline Avoid sour food like curd, pickles etc & 67 & $33.5 \%$ \\
\hline do not exercise during menses & 110 & $55 \%$ \\
\hline Severe Pain during mensus is normal & 69 & $38.5 \%$ \\
\hline Don't drink cold beverages & 76 & $38 \%$ \\
\hline \multicolumn{3}{|c|}{$\begin{array}{c}\text { Table 5. Showing Prevalent Myths and Taboos Related to } \\
\text { Menstruation }\end{array}$} \\
\hline
\end{tabular}

As shown in the table 5 there are many misconceptions about menstruation despite the fact that the students are studying medical education due to lack of awareness and communication. Maximum misconception is regarding that one should not enter temple, touch holy books, do not exercise and should not enter kitchen during menstruation.

\section{DISCUSSION}

235 questionnaires were distributed out of which 200 were retrieved of $85.4 \%$ which is a good response rate. A number of factors such as general health, genetic factors, socioeconomic and nutritional factors determine the age of menarche. ${ }^{7}$ It has been reported that regional and racial differences have a lot of bearing on menarchial age.8,9 Also studies have suggested that menarche tends to appear earlier in life as the sanitary, nutritional and economic conditions of a society improves. ${ }^{10,11}$ The mean age for menarche observed in the present study from SGT Hospital was $12.59 \pm 1.25$ years which was lower compared to the result of other studies. Similar study from south India Mysore reported $13.36 \pm 1.25$ years. ${ }^{12}$. Although small differences are obvious between the reported ages, varying from $13.06 \pm 1.43$ years in West Bengal13 to 13.4, 13.5, and 13.6 years in Goa, Chennai, and East Delhi, respectively.14,15,16,17 Recent reports from many countries of the world indicate a decline in the mean age; the current age as per reports from European and North American countries is 12.5 years, while $12.8 \pm 1.3$ years is from Turkey. ${ }^{18}$ Our study is showing a decline in the menarcheal age lower than the various above studies.

This is similar to study from south India and as medical students coming to the university are a mix of girls from both urban and rural background.

Dysmenorrhoea $140(70 \%)$ is the most common problem associated with female medical students in this study lower compared to other studies. Studies in Ethiopia and Turkey showed a overall prevalence of dysmenorrhoea among students $85.1 \%$ and $89.5 \%$ respectively which was higher than our study. ${ }^{19}$ Recently, it has become an important public health problem among the female population; The proportion of mild, moderate and severe dysmenorrhoea in the present study were 67 (54, 9\%), 49(37.78\%)and 15(12.29\%) respectively while study from Ethiopia showed $47.5 \%, 38.2 \%$ and $14.2 \%$ respectively which was almost comparable. Prevalence of dysmenorrhea among the selected group was $78.2 \%$ and $66.8 \%$ in studies on adolescents from south India ${ }^{20}$ and it was associated to early menarche age; similar observation is reported among Moroccan girls ${ }^{21}$. Probably early onset of menarche leads to earlier ovulatory cycles and an earlier experience of dysmenorrhea. Occurrence of severe pain during menstrual period accounts for $3-20 \%$ in most population. Early menarche could be reason for significantly higher incidence of dysmenorrhoea. Various studies have shown that severity of pain decreases with increase in age, and in older women the frequency of severe pain decreases.

$53.27 \%$ of dysmenorrhoeic women had limitation of their working ability while the south Indian study showed $68.8 \%$ of the participants said their working ability was affected to moderate extent, the association between severity of pain and limited work ability was statistically significant $(P=0.000)$. It is important to know the health problems of the general population so that corrective measures can be incorporated in the health intervention programs; our study has contributed to the current health-related problems of women which curtails their productivity. Although the problem faced by the women is for a short duration, the repetitiveness makes it a serious concern and requires a corrective measure.

The prevalence of PMS in our study was $52 \%$ which was almost similar to the Mysore study was 116 (58\%). But this was less than the prevalence found among Jima University 
students of Ethiopia, ${ }^{22}$ teacher training university students of Iran, ${ }^{23}$ university students of Thailand ${ }^{24}$ and university students of Nigeria $^{25}$ which was $99.6 \%, 98.2 \%, 85.5 \%$ respectively. This difference could be due to the different population studied different study groups, different time of study and different criteria used in different studies.

Other common disorders in present study were abnormal menstrual flow, abnormal duration of flow followed by irregular length of cycle. Our study showed that $34.5 \%$ girls had irregular cycles out of which $24 \%$ had prolonged cycles and $10.5 \%$ had frequent cycles which was significantly higher than the study from Mysore South India where 2.2\% and 4.1\% of the participants had to encompass short and long menstrual periods, respectively. It could be possible that the increase in the incidence of irregularity is due to changes in lifestyle that is being introduced in different spheres of life and various other factors like pollution, pesticides in food and drinking water in large quantities and radiation.

However, higher percentages (7-24\%) of occurrence are reported from Turkey and Nigeria. ${ }^{26}$ In our study 21 (10.5\%) girls had shorter cycles <= 20 days and 48 (24\%) had cycles $>35$ days which is significantly more than in other studies.

Similarly, reports have indicated variations in duration of flow, the mean duration being $5.3 \pm 1.32$ days and stretched to more than 7 days for Indians. One to four percent of women population is reported to have long duration of flow ${ }^{27}$. We found a mean duration of $4.77 \pm 1.06$ days as the normal period of menstrual flow, with $4.1 \%$ of participants having more than 7 days Irregularity in the monthly shedding is also indicated in different studies, percent occurrence from Bangladesh, ${ }^{1}$ Lebanon, ${ }^{27}$ and Gambia ${ }^{28}$ varied from 3 to $16 \%$, whereas studies from India presents a figure of 5 to $9 \% .{ }^{29}$

$121(60.5 \%)$ were aware of menstruation before menarche as compared to the south study of 101 (50.5\%). Awareness regarding menarche is common among young girls and gradually it is increasing in rural area as shown by the figure in our study. The major source of information was mothers, sisters and friends, or the information media, such results were also reported by other works.

Despite the fact that menstrual disorders are so common majority of girls 55(50\%) do self-medication, 20 (18.18\%) took treatment as advised by parents and $35(31.81 \%)$ only consulted the doctor for dysmenorrhoea. The consultation of the doctor only occurred in severe cases.

There are many taboos and superstitions associated with menstruation. only $17.5 \%$ girls had no misconception. $70.5 \%$ do not attend temple, $54 \%$ do not touch holy books, $55 \%$ do not exercise, $38 \%$ do not drink cold beverages, $33.5 \%$ do not touch or take sour food and 38\% consider severe pain as normal which is similar to study by Garg S and Anand T. 30

\section{CONCLUSION}

Dysmenorrhea, PMS, and menstrual irregularity are more prevalent among young females and gradually increasing with time. These problems affect the social and academic life of the college girls. Despite increasing awareness, self-medication is still the rule which may be damaging in the long run. Timely intervention and consultation with the doctor would help in significantly improving the life of the college girls thereby improving the productivity. Timely programs regarding awareness of the disorders of menstruation would help girls cope better and seek proper medical assistance.
The limitation of the present study is that it consists only of College and University students, and may not represent the frequency of dysmenorrhea and other menstrual disorders among young women in the general population.

\section{REFERENCES}

[1] Harlow SD, Campbell OM. Epidemiology of menstrual disorder in developing countries: a systematic review. Br J Obstet Gynaecol 2004;111(1):6-16.

[2] Wateraid.org. Module one: Menstrual Hygiene Basics. 2012. [Last accessed on 2014 Aug 09].

[3] French L. Dysmenorrhoea. American Family Physician 2005;71(2):285-91.

[4] Henderson CW. ACOG issues guidelines on diagnosis and treatment of PMS. Women's Health Weekly 2005;5(6):20-2.

[5] Cerin A, Collins A, Landgren BM, et al. Hormonal and biochemical profiles of premenstrual syndrome. Treatment with essential fatty acids. Acta Obstet Gynecol Scand 1993;72(5):337-43.

[6] Kaiser S. Menstrual Hygiene Management. 2008. [Last accessed on 2014 Aug 09].

[7] Chowdhury S, Shahabuddin AK, Seal AJ. Nutritional status and age at menarche in a rural area of Bangladesh. Ann Hum Biol 2000;27(3):249-56.

[8] The museum of Menstruation and women's health. Average age at menarche in various cultures. [Last accessed on Jul, 2003]. http://www.mom.org

[9] Ayatollahi SM, Dawlatabadi E, Ayatollahi SA. Age at menarche and its correlates in Shiraz, Southern Iran. Iranian J Med Sci 1999;24:20-5.

[10] Kaplowitz P. Pubertal development in girls: Secular trends. Curr Opin Obstet Gynecol 2006;18(5):487-91.

[11] Abioye-Kuteyi EA, Ojofeitimi EO, Aina OI, et al. The influence of socioeconomic and nutritional status on menarche in Nigerian school girls. Nutr Health 1997;11(3):185-95.

[12] Omidvar S, Begum K. Menstrual pattern among unmarried women from south India. J Nat Sci Biol Med 2011;2(2):174-9.

[13] Sanyal S, Ray S. Variation in the menstrual characteristics in adolescents of West Bengal. Singapore Med J 2008;49(7):542-50.

[14] Patel V, Tanksale V, Sahasrabhojanee M, et al. The burden and determinants of dysmenorrhoea: a population-based survey of 2262 women in Goa, India. BJOG 2006;113(4):453-63.

[15] Sheila W, Malathy K, Premila S. Menstrual and gynecological disorders in 500 school girls in Madras city. J Obstet Gynecol India 1993;43:940-5.

[16] Nair P, Grover VL, Kannan AT. Awareness and practices of menstruation and pubertal changes amongst unmarried female adolescents in a rural area of East Delhi. Indian J Community Med 2007;32:156-7.

[17] Grover VL. Final report on a study of reproductive health awareness and sexual behavior among adolescents in Delhi: Report submitted to ICMR: Delhi. 1998. 
[18] Cakir M, Mungan I, Karakas T, et al. Menstrual pattern and common menstrual disorders among university students in Turkey. Pediatrics Int 2007;49(6):938-42.

[19] Shiferaw MT, Wubshet M, Tegabu D. Menstrual problems and associated factors among students of Bahir Dar University, Amhara National Regional State, Ethiopia: a cross sectional survey. Pan Afr Med J 2014; $17: 246$

[20] Omidvar S, Amiri FN, Bakhtiari A, et al. A study on menstruation of Indian adolescent girls in an urban area of South India. J Fam Med Primary Care 2018;7(4):698-702.

[21] Montero P, Bernis C, Loukid M, et al. Characteristics of menstrual cycles in Moroccan girls: prevalence of dysfunctions and associated behaviours. Ann Hum Biol 1999;26(3):243-9.

[22] Tenkir A, Fisseha N, Ayele B. Premenstrual syndrome: prevalence and effect on academic and social performance of students in Jimma University, Ethopia. Ethiop J Health Dev 2003;17(3):181-8.

[23] Nourjah P. Premenstrual syndrome among Teacher Training University students in Iran. J Obstet Gynecol India 2008;58(1):49-52.

[24] Thu M, Diaz EOG, Sawhsarkapaw. Premenstrual syndrome among female university students in Thailand. AU J T 2006;9(3):158-62.
[25] Antai AB, Udezi AW, Ekanem EE, et al. Premenstrual syndrome: prevalence in students of the University of Calabar, Nigeria. African Journal of Biomedical Research 2004;7(2)45-50.

[26] Fakeye O, Adegoke A. The characteristics of the menstrual cycle in Nigerian school girls and the implications for school health programmes. Afr J Med Med Sci 1994;23(1):13-7.

[27] Deeb M, Ghorayeb F, Kabakian-Khasholian T, et al. Measuring gynencological morbidity: evaluating two different data sources from Beirut. Health Care Women Int 2003;24(3):254-65.

[28] Walraven G, Ekpo G, Coleman R, et al. Menstrual disorders in rural Gambia. Stud Fam Plann 2002;33(3):261-8.

[29] Bhatia JC, Cleland J, Bhagavan L, et al. Levels and determinants of gynecological morbidity in a district in south India. Stud Fam Plann 1997;28(2):95-103.

[30] Garg S, Anand T. Menstruation related myths in India: strategies for combating it. J Family Med Prim Care 2015;4(2):184-6. 